\title{
LAÇOS EM FAMÍLIA NA DISCURSIVIDADE DO AFETO
}

\author{
NICOLE CORTE LAGAZZI ${ }^{1}$ \\ EPSI - Espaço Psicanalítico, R. Nevinha Cavalcanti, 46 - Miramar \\ 58043-000 - João Pessoa (PB) - Brasil \\ nicolelagazzi@gmail.com
}

SUZY MARIA LAGAZZI²

Universidade Estadual de Campinas, Instituto de Estudos da Linguagem Departamento de Linguística, Programa de Pós-graduação em Linguística

Cidade Universitária Zeferino Vaz, Barão Geraldo - 13083-970

Campinas (SP) - Brasil - Caixa-postal 6045

$\underline{\text { slagazzilgmail.com }}$

Resumo. Apresentamos uma análise do conto "Feliz Aniversário", de Clarice Lispector (1960), entremeando discurso e inconsciente, análise, psiquê e literatura.

Palavras-chave: Feliz Aniversário; Clarice Lispector; discurso; inconsciente; literatura.

Abstract. We present an analysis of the short story "Happy Birthday" ["Feliz Aniversário"] by Clarice Lispector (1960), interspersing discourse and the unconscious, as well as analysis, psyche and literature.

Keywords: Feliz Aniversário; Clarice Lispector; discourse; unconscious; literature.

Pra Geny Lagazzi, a nossa Augusta.

\section{PEQUENO PRÓLOGO}

Família, um laço que nos une. Entre outros que nos afagam e afogam.

O convite pra escrevermos a quatro mãos nos mobiliza, numa busca de parceria entremeando discurso e inconsciente, análise, psiquê e literatura. Parceria pra falar do

\footnotetext{
${ }^{1}$ Psicóloga clínica - psicanalista. Mestre em Literatura e Psicanálise pela UFPB. Sobrinha da Tia Su.

2 Doutora em Linguística pela Unicamp. Docente do Departamento de Linguística do Instituto de Estudos da Linguagem da Unicamp, onde atua na graduação e na Pós-graduação. Tia da Nick.
} 
sujeito e tantos possíveis sentidos. Parceria de laços em família. Parceria em "laços de família”. Onde vamos nos encontrar? Como?

A sugestão se tornou escolha. O que você acha de partirmos do "Laços de Família", da Clarice, tia? Acho bom! Desafio lançado, as quatro mãos se põem no movimento das palavras. E a família é o que ressoa neste livro de contos, nos (re)unindo e demandando compreensões. Escolhemos Feliz Aniversário como ponto de encontro para nossos traços, e é justamente a partir deste conto em que muito parece faltar, em que a contradição nos diz tanto, que nos lançamos na tarefa de preencher o que nunca estará completo nem inteiro.

Em Feliz Aniversário (1960), a família abre a cena e "aos poucos vai chegando". É a família de Dona Anita que começa a encher a casa no aniversário de 89 anos da matriarca. Uma família reticente, que por vezes se diz em frases prontas, que tentam ser efusivas, que tentam silenciar o que não tem nome. Uma família em que o afeto parece não encontrar lugar. Não nos reconhecemos na família de Dona Anita em sua maneira de festejar e de amar. Mas há algo que nos atrai nesse estranhamento.

\title{
O ESTRANHO EM CENA
}

Noemi Jaffe, em sua apresentação no Café Filosófico, ao discutir outro texto de Lispector - A Legião Estrangeira (1964) - inicia sua fala com uma discussão bastante interessante sobre o estranhamento na obra clariceana. Aponta para o fato da palavra "estranho" referir-se, em nossa fala cotidiana, àquilo que não compreendemos muito bem, que nos parece deslocado dos padrões normais. O que é interessante observarmos, aponta Jaffe, é que a palavra 'estranho' tem a mesma etimologia da palavra extra. E extra significa fora.

\begin{abstract}
Estranho é exatamente isso: aquele que é de fora. Aquele que não pertence, o estrangeiro. Estrangeiro e estranho, na verdade, são palavras sinônimas. Estranho é aquele que não pertence a um grupo, que não pertence a uma determinada comunidade que se autodenominou grupo por alguma razão, por algum hábito comum que este grupo compartilha [...]. Para começarmos a pensar na obra de Clarice Lispector, é importante que a gente compreenda estranho e estranhamento como algo que é de fora, que não pertence a. (JAFFE, 2015)
\end{abstract}

A família de Feliz Aniversário é estranha para nós, somos estrangeiras neste modo de laço, não nos reconhecemos na cena narrada. Mas, ainda assim, algo capturou nosso olhar. "O estranhamento não só repele, ele também fascina. Aliás, por causa do fascínio que o estranhamento exerce, ele também gera repulsa. Porque muitas vezes a gente rejeita aquilo que nos fascina pelo medo que isto possa nos envolver excessivamente" (JAFFE, 2015). A obra de Clarice parece colocar-nos sempre à beira de um abismo, estamos sempre na iminência de sermos lançados para um desconhecido: ao trabalhar com um olhar profundo para as cenas cotidianas, Lispector é capaz de torná-las estranhas para nós. Ao estranharmos a família de Dona Anita, estranhamos a nossa própria - ainda que nos reconhecendo como parte dela.

Freud, em seu texto $O$ Estranho (1919), já de início, alerta sobre o que se relaciona à ideia de estranhamento: "relaciona-se, indubitavelmente com o que é assustador - com o que provoca medo e horror" (p. 237), e completa: "o estranho é aquela categoria do 
assustador que remete ao que é conhecido, de velho, e há muito familiar" (p. 238). Que o novo pode ser estranho e assustador, não restam muitas dúvidas, mas Freud nos chama a atenção justamente para o fato de que algo familiar, já conhecido, pode ser capaz de nos assombrar. Na tentativa de explicar essa ideia paradoxal - de um estranho familiar - Freud retoma a origem e os muitos significados das palavras heimlich e constata que "seu significado se desenvolveu na direção da ambivalência, até que finalmente coincide com seu oposto, unheimilich" (p. 244). O estranhamento faz parte do que nos é familiar.

Como um dos temas de estranheza que mais se destacam, Freud cita o fenômeno do duplo. Para tanto, exemplifica-o na telepatia, na confusão que podemos experimentar diante de uma imagem de nós mesmos e, ainda, diante da repetição constante de algo. Pensamento, imagem e ação. Podemos experienciar o estranhamento na duplicidade do que é familiar. "Esse fenômeno, sujeito a determinadas condições e combinado a determinadas circunstâncias, provoca indubitavelmente uma sensação estranha, que, além do mais, evoca a sensação de desamparo experimentada em alguns estados oníricos" (p. 254). Repetição e desamparo são entrelaçados nesta ideia freudiana de estranho e apresentam-se nos ecos de Feliz Aniversário. A repetição merece, em Feliz Aniversário, uma atenção especial. Uma atenção especial! Clarice repete, repete e repete. São frases, adjetivos, nomes... e sentimentos.

O que a família de Dona Anita está tentando silenciar e que retorna com tanto ruído? O que se repete no texto clariceano que nos estranha e fascina? O que há de familiar no extra-nho da família de Dona Anita? Estranhamento, desconhecimento, reconhecimento, identificação. Um quarteto sobre o qual nos atrevemos!

Louis Althusser, em seu texto Freud e Lacan (1984), retoma Freud para ressaltar "que o sujeito humano é descentrado, constituído por uma estrutura que também tem um 'centro' apenas no desconhecimento imaginário do 'eu', ou seja, nas formações ideológicas em que ele se "reconhece"' (idem, p. 71). Althusser reitera a necessidade de melhor compreensão dessa estrutura do desconhecimento que tanto interessa "a qualquer pesquisa sobre a ideologia" (idem).

O processo de identificação do sujeito resulta da interpelação ideológica do indivíduo, que especificamos como a submissão do sujeito ao significante, na história. A identificação nos permite compreender que para o sujeito fazer sentido no mundo ele não precisa ser a fonte da interpretação, o centro de onde emana todo e qualquer pensamento, decisão e vontade, tal como as perspectivas idealistas afirmam. Fazer sentido no mundo e dar sentido ao mundo, na perspectiva materialista à qual nos filiamos, é se identificar em uma determinada posição de sujeito, em percursos de sentidos anteriores a cada um de nós, embora nos pareça que o sentido "brote" de nossa vontade. Identificar-se é se (re)conhecer em sentidos que nos acolhem na evidência de que "só pode ser assim", se conhecer na reafirmação de interpretações que não demandam qualquer explicação. Dessa forma, o sujeito significa e se significa dentro de possibilidades determinadas no confronto de diferentes posições na história. Ou seja, para se identificar, o sujeito necessariamente desconhece outras possibilidades de reconhecimento, tomado na evidência da posição que o constitui. Ser sujeito é se constituir na alteridade. Só posso ser 'eu' porque há o 'Outro' e os 'outros'. Um sentido só pode ser afirmado porque muitos outros se diferenciam dele. Para dizer é preciso deixar de dizer. Mas essa captura do sujeito na evidência dos sentidos que o constituem em uma determinada posição é sempre falha, pois a incompletude e a contradição são a base do processo de interpelação. Incompletude da língua(gem) e contradição da história. Nunca acabamos de dizer, o 
sentido sempre está em movimento, o simbólico nunca se fecha, o desejo nunca se realiza plenamente, já que o objeto de desejo será sempre apenas temporariamente preenchido. E esse nunca acabar de dizer tem lugar num social recortado por diferentes condições de produção, o que impede qualquer síntese de satisfazer a todos. As sínteses se afirmam e legitimam pela autoridade e coerção de alguns sentidos sobre outros, algumas interpretações sobre outras, alguns processos de identificação sobre outros ${ }^{3}$.

$\mathrm{Na}$ falha constitutiva da identificação do sujeito está posto o estranhamento. Voltaremos a este ponto.

Ainda em Freud e Lacan (idem), Althusser retoma Lacan para pontuar o que considera ser a grande contribuição e descoberta do autor e que diz respeito ao fato de que na passagem da existência biológica à existência humana, é sob a lei da linguagem que se fixa e se dá toda a ordem humana. Falando dos dois grandes momentos dessa passagem do biológico ao humano, Althusser especifica que o primeiro é aquele em que a criança vive com a mãe "essa relação dual no modo do fascínio imaginário do ego, sendo ela [a criança] [...] todos os outros da identificação narcísica primária, sem jamais poder tomar, face ao outro ou a si mesma, a distância objetivante do terceiro" (ALTHUSSER, 1984, p. 64).

Para o trabalho com a linguagem, a compreensão da estrutura ternária, que caracteriza o segundo momento da passagem do biológico ao humano segundo Althusser, é muito importante para que a relação com os sentidos se abra para a polissemia. Este segundo momento, o "do Édipo",

no qual surge uma estrutura ternária no fundo da estrutura dual, quando o terceiro (o pai) se imiscui, como um intruso, na satisfação imaginária do fascínio dual, perturba a sua economia, quebra os seus fascínios, e introduz a criança nisso a que Lacan chama a Ordem Simbólica, a da linguagem objetivante, que lhe permitirá dizer finalmente: eu, tu, ele ou ela, que permitirá, pois, ao serzinho situar-se como criança humana num mundo de terceiros adultos. (ALTHUSSER, 1984, p. 65)

O primeiro momento é o momento do imaginário e o segundo momento é o do simbólico, sintetiza Althusser, ressaltando o que Lacan esclareceu: os "dois momentos são dominados e marcados por uma única Lei, a do Simbólico [...] sob a própria forma da Ordem do significante, ou seja, sob a forma de uma Ordem formalmente idêntica à ordem da linguagem" (idem, p. 65).

Esta retomada de Lacan via Althusser, embora deixe de pontuar questões caras à psicanálise, nos permite uma entrada interessante na discussão do estranhamento, no enlace entre ideologia e inconsciente.

Pêcheux (1990), quando discute os processos revolucionários e nos mostra que a eficácia da dominação está na identificação do sujeito com essa dominação como um processo interno a ele, toca num ponto de grande sensibilidade para pensarmos a relação entre reprodução e transformação, entre reiteração e deslocamento dos sentidos.

\footnotetext{
3 Sobre o processo de interpelação e identificação ver Althusser em Aparelhos Ideológicos de Estado (1985), e Pêcheux em Semântica e Discurso (1988), especificamente o Anexo III, e em "Delimitações, Inversões, Deslocamentos" (1990).
} 
Nesse mesmo texto, o autor vai nos falar do "alhures" enquanto o irrealizado que pode vir a fazer sentido, pode vir a se realizar rompendo um efeito de fronteira. Pêcheux fala do alhures na linguagem, ressaltando o papel desta no processo de interpelação ideológica do sujeito. Ser interpelado é se constituir sujeito pela submissão à língua na história. Mas nenhuma submissão é plena. A falha é constitutiva do ritual da interpelação. Pêcheux reitera a interpelação como um ritual simbólico, estruturado na incompletude da linguagem e na contradição da história, abrindo espaço para a brecha, para $\mathrm{o}$ deslocamento, para o estranhamento. O estranhamento que nos é tão familiar!

O familiar e o estranho se entrelaçam no irrealizado da linguagem, no desconhecimento do discurso do inconsciente e de suas razões intangíveis: "só há causa daquilo que falha", retoma Pêcheux (1988, p. 300) o aforismo lacaniano. estranhamento?

O que nos estranha em Feliz Aniversário? O que há de familiar nesse

\section{FELIZ ANIVERSÁRIO. O SILÊNCIO QUE AFAGA E AFOGA}

Feliz Aniversário é um dos treze contos que compõem Laços de Família, obra de 1960. A matriarca da família, Dona Anita, está fazendo oitenta e nove anos e seus aniversários são o momento do ano em que todos se reúnem. Clarice nos abre a casa de Dona Anita e os convidados vão chegando, aos poucos. A primeira foi a nora de Olaria, cujo marido não viera "pela óbvia razão de que não queria ver os irmãos" e "mandara a mulher para que nem todos os laços fossem cortados". Observações que dão o tom na apresentação dessa família que se pauta por antagonismos. Na sequência a nora de Ipanema, cujo marido viria depois... Olaria e Ipanema, espaços totalmente estranhos um ao outro, representados por noras totalmente estranhas uma à outra. A única coincidência: os maridos ausentes!

Quando a nora de Ipanema pensou que não suportaria nem um segundo mais a situação de estar sentada defronte da concunhada de Olaria que cheia das ofensas passadas não via um motivo para desfitar desafiadora a nora de Ipanema - entraram enfim José e a família. E mal eles se beijavam, a sala começou a ficar cheia de gente que ruidosa se cumprimentava como se todos tivessem esperado embaixo o momento de, em afobação de atraso, subir os três lances de escada, falando, arrastando crianças surpreendidas, enchendo a sala - e inaugurando a festa. (LISPECTOR, 1960, p. 56)

José tornou-se o filho mais velho, depois da morte de Jonga.

— Nem todos têm o privilégio e o orgulho de se reunirem em torno da mãe, pigarreou José lembrando-se de que Jonga é quem fazia os discursos. [...] José esperando de si mesmo com perseverança e confiança a próxima frase do discurso. Que não vinha. Que não vinha. Que não vinha. Os outros aguardavam. Como Jonga fazia falta nessas horas - José enxugou a testa com o lenço - como Jonga fazia falta nessas horas! Também fora o único a quem a velha sempre aprovara e respeitara, e isso dera a Jonga tanta segurança. E quando ele morrera, a velha nunca mais falara nele, pondo um muro entre sua morte e os outros. Esquecera-o talvez. Mas não esquecera aquele mesmo olhar firme e direto com que desde sempre olhara os outros filhos, fazendo- 
os sempre desviar os olhos. Amor de mãe era duro de suportar: José enxugou a testa, heroico, risonho. (LISPECTOR, 1960, p. 64-65)

O filho Manoel, sócio de José, veio acompanhado pela mulher que, sempre atenta, o observava, sem nenhum sorriso, sem nenhuma palavra. Cordélia, a nora mais nova, que sorria ausente. Os netos, a vizinha, e todos recepcionados pela anfitriã, Zilda - filha com quem Dona Anita morava. A cena da festa vai tomando corpo conforme a casa enche. O não-dito paira sobre a atmosfera da festa. Todos os anos são reatualizados os elogios fáceis, as piadas prontas e os comentários vagos que perpassam os assuntos superficiais. Repara-se no vestido de uma e nos salgadinhos poucos que são servidos. E junto com os convidados entram também os nós que amarram os laços de família. Que nós são esses em meio aos laços? Como se significam os laços?

Uma família que se desencontra também na hora do 'parabéns':

então acenderam a vela. E então José, o líder, cantou com muita força, entusiasmando com um olhar autoritário os mais hesitantes ou surpreendidos, "vamos! todos de uma vez!" - e todos de repente começaram a cantar alto como soldados. Despertada pelas vozes, Cordélia olhou esbaforida. Como não haviam combinado, uns cantaram em português e outros em inglês. Tentaram então corrigir: e os que haviam cantado em inglês passaram a português, e os que haviam cantado em português passaram a cantar bem baixo em inglês. (LISPECTOR, 1960, p. 58)

Um desencontro em que o afeto fica silenciado. Insistimos no que nos desconcerta e estranha... Como se dá a relação entre laço e afeto nessa família? Onde se estruturam os laços? No imaginário de família que nos habita a contradição é estruturante. Em nosso pequeno prólogo falamos dos laços que afagam e afogam. Nesse desconhecimento que beira sempre o reconhecimento entre o familiar e o estranho, somos lançadas de encontro a essa família que nos atrai e provoca.

Eles se mexiam agitados, rindo, a sua família. E ela era a mãe de todos. E se de repente não se ergueu, como um morto se levanta devagar e obriga mudez e terror aos vivos, a aniversariante ficou mais dura na cadeira, e mais alta. Ela era a mãe de todos. E como a presilha a sufocasse, ela era a mãe de todos e, imponente à cadeira, desprezavaos. E olhava-os piscando. (LISPECTOR, 1960, p. 60)

Contrastando com a agitação da família, nos deparamos com o silêncio rígido da aniversariante, sentada à cabeceira da mesa, desde muito cedo, observando. A velha pouco fala em sua festa de aniversário e, em seu silêncio, enxerga a família com desdém e distância. O silêncio de Dona Anita parece ser um estrondo de verdade que ecoa na narrativa: o peito vazio - apenas soando rancor - orienta a aparência de Dona Anita: "tratava-se de uma velha grande, magra, imponente e morena. Parecia oca." (p. 56). Nome próprio bastante contrastante com a descrição que lhe é dada. Anita é comumente conhecido como diminutivo de Ana que, por sua vez, significa "cheia de graça". Nome deslocado para a personagem que Clarice nos apresenta. "Velha", significante que se repete incessantemente para nomear a matriarca silenciosa, marca a personagem.

A mudez de Dona Anita é quebrada em pouquíssimas frases. A matriarca que tudo observa, com ar de rancor e desdém, rompe seu silêncio e ganha travessão e direito de se dizer em primeira pessoa em poucos momentos. Mas são momentos cruciais que 
confirmam a narrativa em terceira pessoa, que fazem da voz do narrador um dos membros da família.

Todas [as noras] vaidosas e de pernas finas, com aqueles colares falsificados de mulher que na hora não aguenta a mão, aquelas mulherezinhas que casavam mal os filhos, que não sabiam pôr uma criada em seu lugar, e todas elas com as orelhas cheias de brincos nenhum, nenhum de ouro! A raiva a sufocava.

- Me dá um copo de vinho! disse.

O silêncio se fez de súbito, cada um com o copo imobilizado na mão.

- Vovozinha, não vai lhe fazer mal? insinuou cautelosa a neta roliça e baixinha.

- Que vovozinha que nada! explodiu amarga a aniversariante.

- Que o diabo vos carregue, corja de maricas, cornos e vagabundas! me dá um copo de vinho, Dorothy! - ordenou.

(LISPECTOR, 1960, p. 61-62)

Dona Anita rompe o silêncio para dizer em exclamação! Ao ganhar o poder da primeira pessoa, cala e interrompe a própria festa. Depois de fazer ouvida sua voz, o silêncio novamente encontra lugar, agora em seu olhar. "Seu olhar estava fixo, silencioso. Como se nada tivesse acontecido." (p. 62). O silêncio da velha não é vazio. Talvez por isso mesmo nos estranhe e nos perturbe. Página após página ficamos na iminência de mais uma fala, de mais um susto.

Laços que afagam e afogam, sufocam e dão novo fôlego.

\section{NA BRECHA DA REPETIÇÃO}

Desprezo, rancor e cólera se emaranham e vão tecendo o olhar da velha:

Todos aqueles seus filhos e netos e bisnetos que não passavam de carne de seu joelho, pensou de repente como se cuspisse. Rodrigo, o neto de sete anos, era o único a ser a carne de seu coração, Rodrigo, com aquela carinha dura, viril e despenteada. Cadê Rodrigo? Rodrigo com olhar sonolento e entumecido naquela cabecinha ardente, confusa. Aquele seria um homem. Mas, piscando, ela olhava os outros, a aniversariante. Oh o desprezo pela vida que falhava. Como?! como tendo sido tão forte pudera dar à luz aqueles seres opacos, com braços moles e rostos ansiosos? Ela, a forte, que casara em hora e tempo devidos com um bom homem a quem, obediente e independente, ela respeitara; a quem respeitara e que lhe fizera filhos e lhe pagara os partos e the honrara os resguardos. O tronco fora bom. Mas dera aqueles azedos e infelizes frutos, sem capacidade sequer para uma boa alegria. Como pudera ela dar à luz aqueles seres risonhos, fracos, sem austeridade? $\mathrm{O}$ rancor roncava no seu peito vazio. Uns comunistas, era o que eram; uns comunistas. Olhou-os com sua cólera de velha. Pareciam ratos se acotovelando, a sua família. Incoercível, virou a cabeça e com força insuspeita cuspiu no chão. (LISPECTOR, 1960, p. 60)

Silenciosamente a aniversariante vai remoendo o seu desprezo, até cuspi-lo com a força do rancor que lhe enche o peito. $O$ desprezo é proporcional à falta de vida que Dona Anita enxerga em sua família. Aqueles "seres opacos, com braços moles e rostos ansiosos", "aqueles azedos e infelizes frutos, sem capacidade sequer para uma boa 
alegria"! Opacidade, moleza, azedume. Falta uma "boa alegria". Uma família que "falha", assim como a sua vida. Família e vida se entrelaçam. Uma família que "falha" ao não conseguir lhe dar vida. A vida que passou? A vida e a família se emaranham na proximidade da morte que sufoca, assim como a presilha.

Mas nem só da "carne de seu joelho" se fizeram os frutos. Seu coração também se tornara carne no neto Rodrigo. "Rodrigo, com aquela carinha dura, viril e despenteada. Cadê Rodrigo? Rodrigo com olhar sonolento e entumecido naquela cabecinha ardente, confusa. Aquele seria um homem." Rodrigo irrompe em meio "aos outros" numa brecha de afeto. Rodrigo carrega a promessa de levar a família adiante, é a esperança de uma nova geração: "aquele seria um homem"! A falta se marca na busca que se formula em pergunta: "Cadê Rodrigo?" O amor por Rodrigo faz ressoar o amor por Joca. Rodrigo ocupa o lugar que o falecido filho Joca ocupara outrora. Rodrigo é o nome do silêncio da morte de Joca.

Em meio a todo o seu desprezo, Dona Anita busca o neto. A "carinha" dura, viril e despenteada, a "cabecinha" ardente e confusa. Imagens ternas marcadas no diminutivo. Ao perguntar por Rodrigo, Dona Anita pergunta pelo afeto. Cadê o afeto? Desprezo, rancor, cólera e afeto. O familiar e o estranho juntos.

Quando nos detemos nos sentimentos de Dona Anita, vemos desprezo, rancor e cólera em profusão, cuspidos com "força insuspeita" pela velha. Vemos a brecha de afeto pelo neto, que quebra a sequência dos pensamentos de Dona Anita, como uma tomada de fôlego no remoer dos ódios. E o amor? O amor não é dito na memória de seu casamento. Dona Anita "casara em hora e tempo devidos com um bom homem a quem, obediente e independente, ela respeitara; a quem respeitara e que lhe fizera filhos e lhe pagara os partos e lhe honrara os resguardos". Hora e tempo devidos, um bom homem, obediência, respeito, honra, deveres cumpridos compõem o "bom tronco". A "boa alegria" reclamada pela velha parece ser uma falta já-lá. Desde sempre a falta parece constituir o tronco. Falta que resultara em profusão de desprezo, raiva e cólera, falta materializada nas perguntas inconformadas.

\footnotetext{
"Como?! como tendo sido tão forte pudera dar à luz aqueles seres opacos, com braços moles e rostos ansiosos? Ela, a forte, que casara em hora e tempo devidos com um bom homem a quem, obediente e independente, ela respeitara; a quem respeitara e que lhe fizera filhos e lhe pagara os partos e lhe honrara os resguardos. O tronco fora bom." [...] "Como pudera ela dar à luz aqueles seres risonhos, fracos, sem austeridade?” (LISPECTOR, 1960, p. 60)
}

Essas perguntas reverberam na pergunta por Rodrigo. Como pode tanta força derivar em fraqueza e falta? Cadê o afeto? Onde está o amor? E o filho José que nos lembra que "amor de mãe é duro de suportar". Falta de afeto, falta de amor, são efeitos produzidos pela família de que Clarice se ocupa em seu conto. O ponto em que não nos reconhecemos.

Mas essas faltas fazem a vida "falhar". Clarice nos traz o desprezo de Dona Anita pela "vida que falhava". Pêcheux (1988) nos lembra, como vimos acima, que todo ritual é falho, que todo ritual se abre em brechas que constituem os processos de identificação e se constituem em pontos de ancoragem para deslocamentos nessas identificações. 
As perguntas inconformadas que irrompem na fala de Dona Anita são brechas que deixam vazar um pouco de amor em meio ao ódio, um amor represado. Dona Anita se ancora em sua força. A família patina em busca da "frase certa".

E de repente veio a frase:

- Até o ano que vem! disse José subitamente com malícia, encontrando, assim, sem mais nem menos, a frase certa: uma indireta feliz! Até o ano que vem, hein?, repetiu com receio de não ser compreendido. Olhou-a, orgulhoso da artimanha da velha que espertamente sempre vivia mais um ano.

- No ano que vem nos veremos diante do bolo aceso! Esclareceu melhor o filho Manoel, aperfeiçoando o espírito do sócio. Até o ano que vem, mamãe! e diante do bolo aceso! disse ele bem explicado, perto de seu ouvido, enquanto olhava obsequiador para José. E a velha de súbito cacarejou um riso frouxo, compreendendo a alusão. Então ela abriu a boca e disse:

- Pois é.

Estimulado pela coisa ter dado tão inesperadamente certo, José gritoulhe emocionado, grato, com os olhos úmidos:

- No ano que vem nos veremos, mamãe!

— Não sou surda! disse a aniversariante rude, acarinhada.

(LISPECTOR, 1960, p. 65-67)

É marcante a repetição em Feliz Aniversário. São frases impactantes que aparecem, duas, três, quatro vezes ao longo do texto; quase sempre muito próximas. Como se apenas esperassem que as lêssemos para, logo em seguida, reverberarem nas paredes do texto e saltarem novamente. E assim, o eco vai se fazendo.

A repetição sistemática dos significantes vai adquirindo caráter de instrumento capaz de produzir estranhamento. Como se um empuxo nos levasse sempre de volta para um determinado lugar. Lispector faz o que Freud outrora notou: "Daquilo que tenho observado, esse fenômeno [da repetição], sujeito a determinadas condições e determinadas circunstâncias, provoca indubitavelmente uma sensação estranha, que, além do mais, evoca a sensação de desamparo experimentada em alguns estados oníricos" (1919, pág. 254) e, mais adiante, completa "a não ser que o indivíduo seja totalmente impermeável ao engodo da superstição, ficará tentado a atribuir um significado secreto a essa ocorrência obstinada" (1919, p. 255). A repetição chama nosso olhar, faz ecoar nossa leitura.

A velha não se manifestava.

Alguns não haviam lhe trazido presente nenhum. Outros trouxeram saboneteira, uma combinação de jérsei, uma broche de fantasia, um vasinho de cactos - nada, nada que a dona da casa pudesse aproveitar para si ou para seus filhos, nada que a própria aniversariante pudesse realmente aproveitar constituindo assim uma economia: a dona da casa guardava os presentes, amarga irônica.

- Oitenta e nove, repetiu Manoel aflito, olhando para a esposa.

A velha não se manifestava.

(LISPECTOR, 1960, p. 56-57)

O punho mudo e severo sobre a mesa dizia para a infeliz nora que sem remédio amava talvez pela última vez: É preciso que se saiba. É preciso que se saiba. Que a vida é curta. Que a vida é curta.

(LISPECTOR, 1960, p. 64) 
Qual o significado da repetição em Feliz Aniversário? Seria ela um sintoma nesses laços familiares? Uma repetição que nos faz ouvir para além do mesmo. Entre a gritaria das crianças brincando e as frases que se repetem vamos escutando, ao longe, o que não pode ser dito.

A contradição toma corpo na repetição. A "frase certa" que veio "de repente", "sem mais nem menos", depois de tanta procura! A mãe, "a velha que espertamente sempre vivia mais um ano", de súbito cacareja um riso frouxo, que vacila entre a resposta rude e a tentativa de carinho. Uma família que em meio a tantos desencontros consegue, enfim, sorrir, se emocionar.

Os filhos se olharam rindo, vexados, felizes. A coisa tinha dado certo. As crianças foram saindo alegres, com o apetite estragado. [...]

Adeus, até outro dia, precisamos nos ver. Apareçam, disseram rapidamente. Alguns conseguiram olhar nos olhos dos outros com uma cordialidade sem receio. Alguns abotoavam os casacos das crianças, olhando o céu à procura de um sinal do tempo. Todos sentindo obscuramente que na despedida se poderia talvez, agora sem perigo de compromisso, ser bom e dizer aquela palavra a mais - que palavra? Eles não sabiam propriamente, e olhavam-se sorrindo, mudos. Era um instante que pedia para ser vivo. Mas que era morto. Começaram a se separar, andando meio de costas, sem saber como se desligar dos parentes sem brusquidão.

- Até o ano que vem! repetiu José a indireta feliz, acenando a mão com vigor efusivo, os cabelos ralos e brancos esvoaçavam. Ele estava era gordo, pensaram, precisava tomar cuidado com o coração. Até o ano que vem! gritou José eloquente e grande, e sua altura parecia desmoronável. Mas as pessoas já afastadas não sabiam se deviam rir alto para ele ouvir ou se bastaria sorrir mesmo no escuro. Além de alguns pensarem que felizmente havia mais do que uma brincadeira na indireta e que só no próximo ano seriam obrigados a se encontrar diante do bolo aceso; enquanto que outros, já mais no escuro da rua, pensavam se a velha resistiria mais um ano ao nervoso e à impaciência de Zilda, mas eles sinceramente nada podiam fazer a respeito: "Pelo menos noventa anos", pensou melancólica a nora de Ipanema. "Para completar uma data bonita", pensou sonhadora.

(LISPECTOR, 1960, p. 65-67)

Uma felicidade vexada une os filhos num olhar. Quase um choro, um regozijo, quase um gozo. "A coisa tinha dado certo". Importa menos o que tinha dado certo. Importa o certo, mesmo sem querer! $O$ 'adeus' se emenda ao 'até outro dia', no esforço da afirmação de que deveriam se encontrar. "Apareçam [...]" Um imperativo rápido e pálido, tal como aqueles "seres opacos, com braços moles e rostos ansiosos", "aqueles azedos e infelizes frutos, sem capacidade sequer para uma boa alegria".

"Alguns conseguiram olhar nos olhos dos outros com uma cordialidade sem receio." O receio que constrangia fez uma trégua, "obscuramente" esquecendo o "perigo do compromisso", e abriu espaço para "aquela palavra a mais" que eles não sabiam qual era, que não veio e os deixou "mudos", "sorrindo". Um instante entre a vida e a morte. Afeto que patina, sem conseguir matar a morte. Mas algo vaza e o gozo espreita.

“- Até o ano que vem! repetiu José a indireta feliz, acenando a mão com vigor efusivo, os cabelos ralos e brancos esvoaçavam." Como responder àquele vigor efusivo 
que estranhava? Seria preciso um "riso alto" ou bastaria um sorriso "mesmo no escuro"? Na contradição do (des)afeto, a frase certa, que marcava o constrangimento da obrigação do encontro no próximo ano diante do bolo aceso, a dúvida em relação à capacidade de resistência da velha a mais um ano de vida, e também o desejo de que ela pelo menos chegasse aos noventa "para completar uma data bonita". A morte entranhando a vida na contradição.

\section{O ENLACE QUE FICA}

A ausência de palavras na boca de Dona Anita parece marcar a presença da morte que se anuncia.

Ninguém poderia adivinhar o que ela pensava. E para aqueles que junto da porta ainda olharam uma vez, a aniversariante era apenas o que parecia ser: sentada à cabeceira da mesa imunda, com a mão fechada sobre a toalha como encerrando um cetro, e com aquela mudez que era sua última palavra. (LISPECTOR, 1960, p. 64)

Nessa cadeia entre o tão pouco dito e o tanto não-dito, em Feliz Aniversário, o olhar diz muito e compõe, com a mudez e o silêncio, a falta e a falha. $\mathrm{O}$ olhar marca muito do que não consegue ser dito na contradição entre o ódio e o amor, entre a vida e a morte.

E o que fica por dizer? O desprezo, a raiva, a cólera estão explicitados e cuspidos. $\mathrm{O}$ inconformismo tem lugar de honra. O amor é duro de suportar. A emoção insiste e consegue, na ambiguidade da frase certa, umedecer os olhos, sorrir os rostos. Novamente nos perguntamos: O que não está dito em Feliz Aniversário? Uma pergunta que vale pelo que faz estranhar na discursividade do afeto. Um desconhecimento que constitui o reconhecimento que nos seduz em Feliz Aniversário e que buscamos compreender.

Nesse entroncamento bordejamos o significante irrepresentável da morte. A morte de Dona Anita que se aproxima, fazendo ecoar, insistentemente, a frase "até o ano que vem" durante as despedidas dos convidados. "Começaram a se separar, andando meio de costas, sem saber como se desligar dos parentes sem brusquidão" (LISPECTOR, 1960, p. 66). Ver a morte de frente é duro de suportar. Duro de suportar.

\section{REFERÊNCIAS}

ALTHUSSER, L. Aparelhos Ideológicos de Estado. Rio de Janeiro: Graal, 1985.

. Freud e Lacan. Marx e Freud. Rio de Janeiro: Graal, 1984.

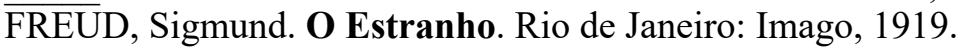

JAFFE, Noemi. A legião estrangeira de Clarice Lispector e o efeito do estranhamento. Café Filosófico, 2015. Duração 105 min. Disponível em https://www.youtube.com/watch?v=Vy0W7HK9O1U. Acesso em abril de 2016.

LISPECTOR, Clarice. (1960). Feliz Aniversário. Em: Laços de Família. Rio de Janeiro: Rocco, 1998.

. A Legião Estrangeira. Rio de Janeiro, Editora do Autor, 1964.

PÊCHEUX, M. Semântica e Discurso: uma crítica à afirmação do óbvio. Campinas: Ed. da Unicamp, 1988.

. Delimitações, Inversões, Deslocamentos. Caderno de Estudos Linguísticos, Campinas, (19), 7-24, jul./dez. 1990. 
Artigo recebido em: março de 2018.

Aprovado e revisado em: setembro de 2018.

Publicado em: dezembro de 2018.

\section{Para citar este texto:}

LAGAZZI, Nicole Corte; LAGAZZI, Suzy Maria. Laços em família. Na discursividade do afeto. Entremeios [Revista de Estudos do Discurso, ISSN 2179-3514, on-line, www.entremeios.inf.br], Seção Temática [Discurso, arte e literatura - Parte II], Programa de Pós-Graduação em Ciências da Linguagem (PPGCL), Universidade do Vale do Sapucaí (UNIVÁS), Pouso Alegre (MG), vol. 17, p. 301-312, jul. - dez. 2018.

DOI: http://dx.doi.org/10.20337/ISSN2179-3514revistaENTREMEIOSvol17pagina301a312 